\title{
Alginate and chitosan particles are drug delivery system for cell therapy
}

\author{
Gianni Ciofani • Vittoria Raffa • Arianna Menciassi • \\ Paolo Dario
}

Published online: 18 June 2008

(C) Springer Science + Business Media, LLC 2008

The publisher regrets that the following figures published in Biomedical Microdevices 10:2, pp. 131-140 by Gianni Ciofani, Vittoria Raffa, Arianna Menciassi and Paolo Dario should have printed in color. Please see below for color figures.

The online version of the original article can be found at http://dx.doi. org/10.1007/s10544-007-9118-7.

G. Ciofani $\cdot$ V. Raffa $\cdot$ A. Menciassi $\cdot$ P. Dario

CRIM Lab-Center for Research In Microengineering,

Scuola Superiore Sant'Anna,

Piazza Martiri della Libertà, 33,

56127 Pisa, Italy

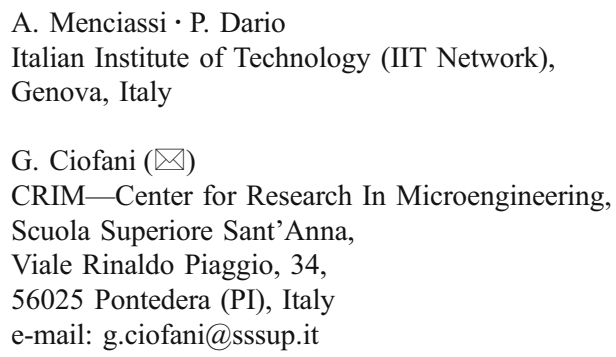


Fig. 1 (a) FIB imaging of alginate particles; (b) FIB imaging of chitosan particles; (c) size distribution of alginate particles (mean radius $\bar{r}=650 \mathrm{~nm}$, standard deviation $\sigma=230 \mathrm{~nm}$ ); (d) size distribution of chitosan particles (mean radius $\bar{r}=650 \mathrm{~nm}$, standard deviation $\sigma=270 \mathrm{~nm}$ )
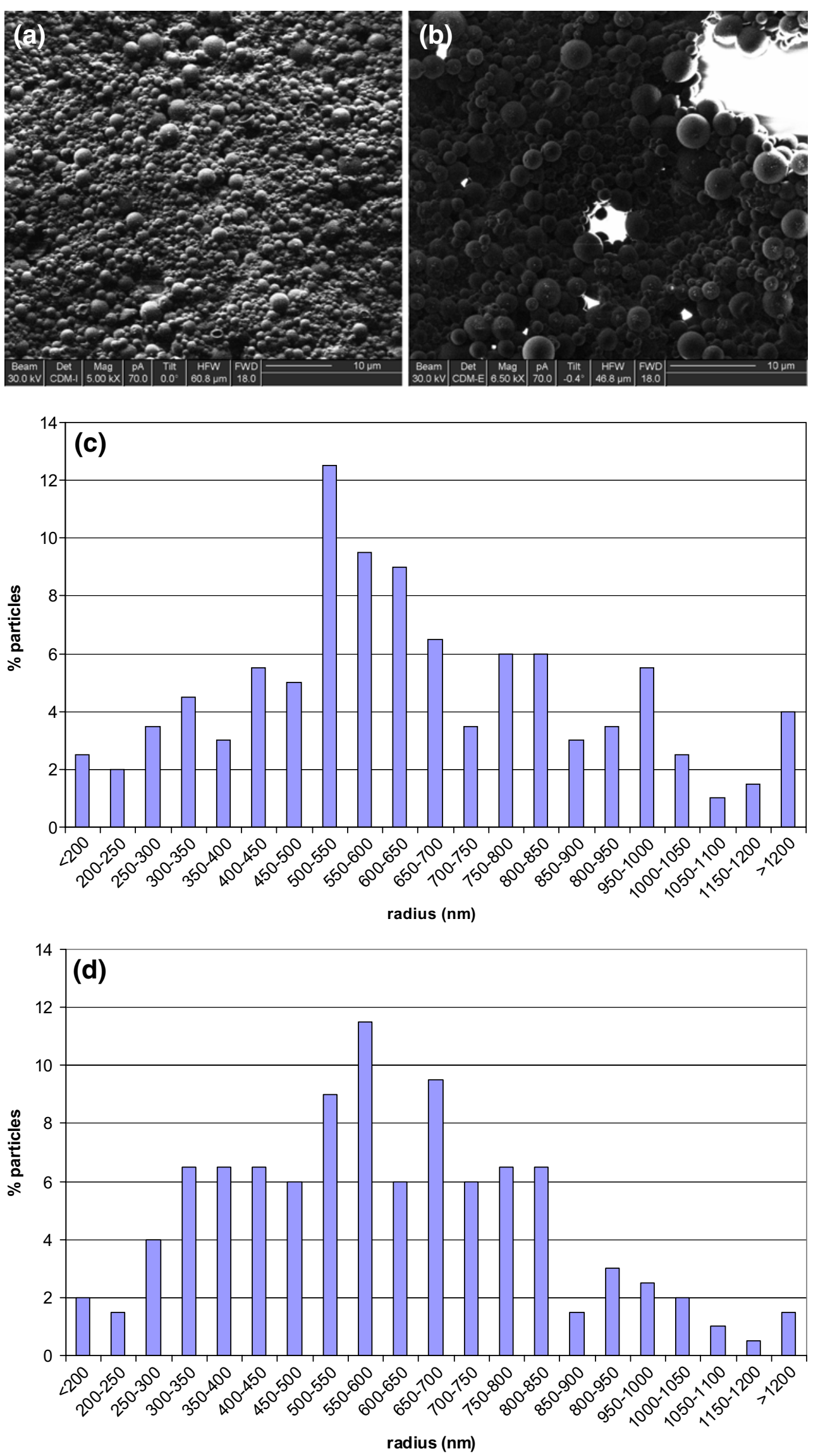
Fig. $2 \mathrm{HN} 9.10 \mathrm{e}$ cells up-take of alginate $(\mathbf{a}, \mathbf{b}, \mathbf{c})$ and chitosan (d, e, f) particles: cells after $4 \mathrm{~h}$ of incubation with particles (a, d); cells after $8 \mathrm{~h}(\mathbf{b}, \mathbf{e})$ and after $20 \mathrm{~h}(\mathbf{c}, \mathbf{f})$ of incubation with particle-free growth medium. Magnification $\times 40$. Circles underline particles within the cells

Fig. $3 \mathrm{CrFK}$ cells up-take of alginate $(\mathbf{a}, \mathbf{b}, \mathbf{c})$ and chitosan (d, e, f) particles: cells after $4 \mathrm{~h}$ of incubation with particles (a, d); cells after $8 \mathrm{~h}(\mathbf{b}, \mathbf{e})$ and after $20 \mathrm{~h} \mathrm{(c,} \mathrm{f)} \mathrm{of} \mathrm{incubation} \mathrm{with}$ particle-free growth medium. Magnification $\times 40$. Circles underline particles within the cells
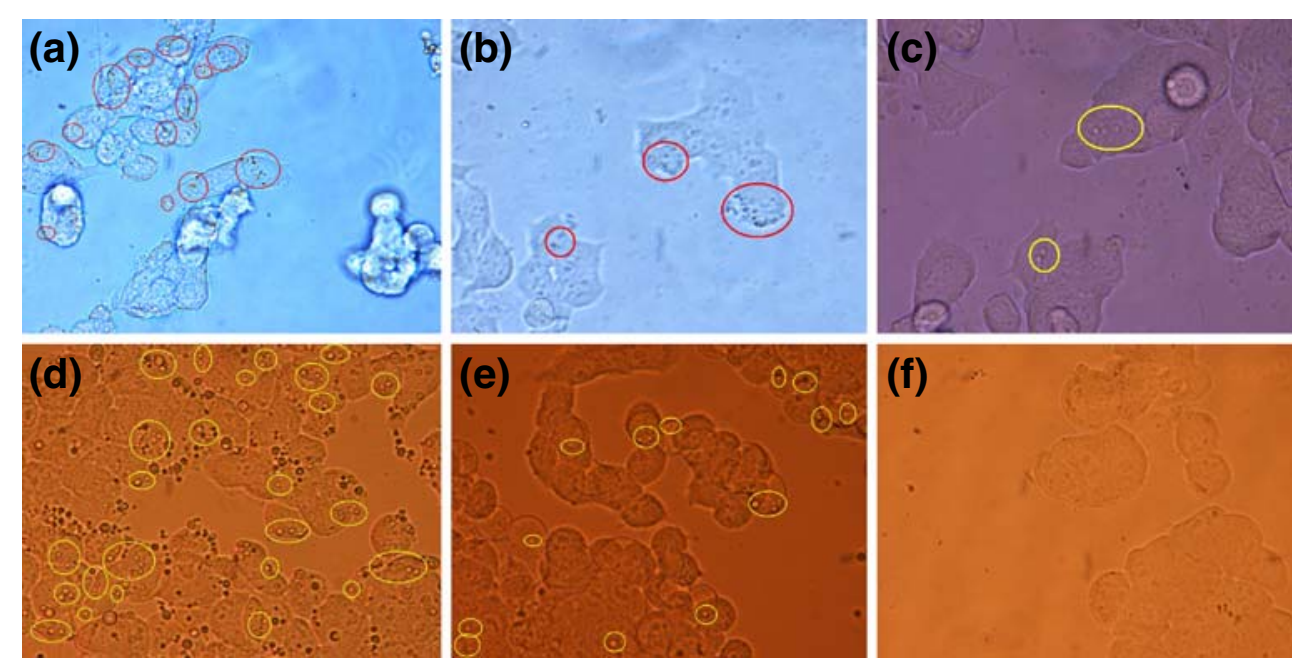
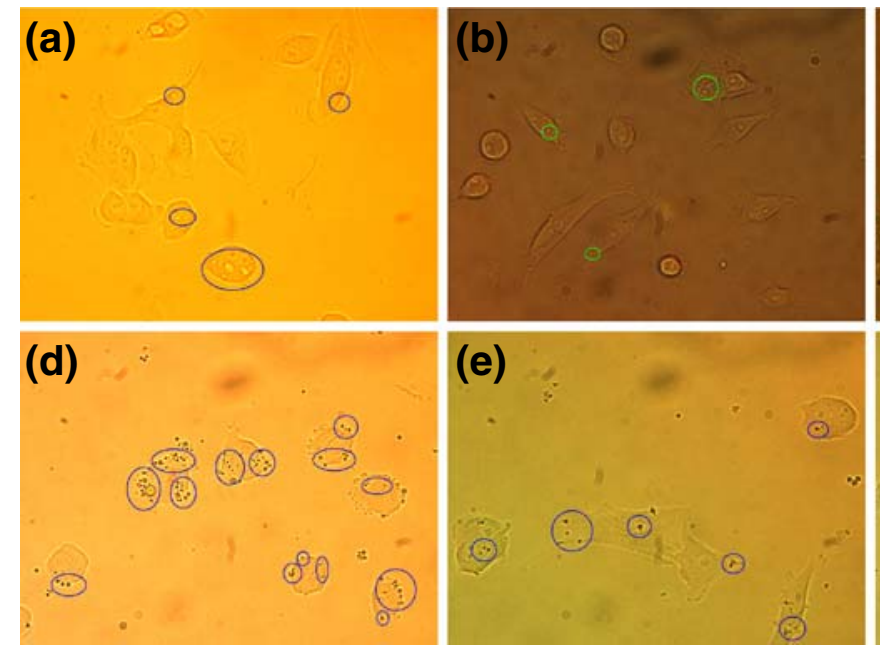

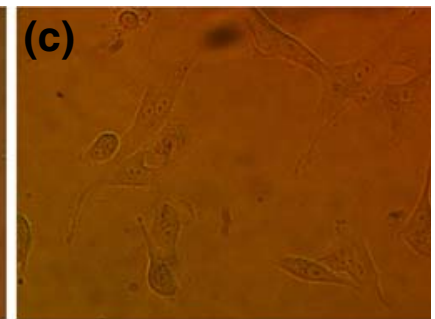

(f)

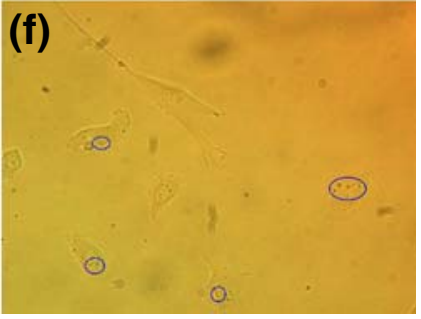



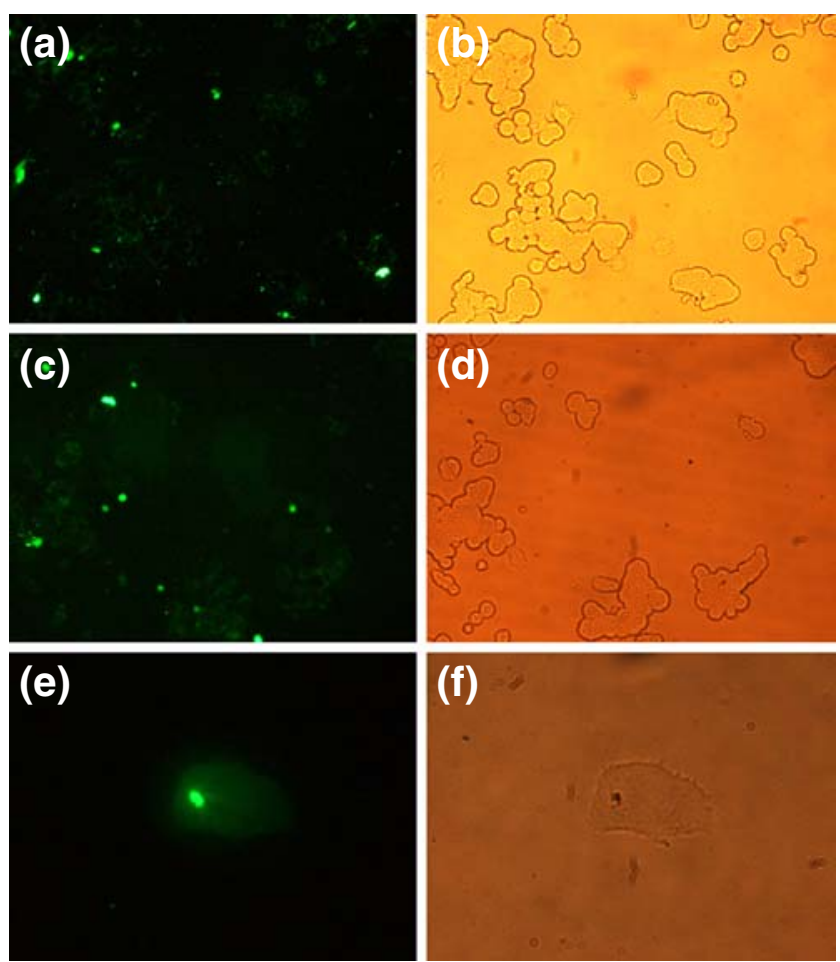

Fig. 5 Fluorescein loaded particles up-taken by HN9.10e cells. Fluorescent and phase-contrast images $(\times 20)$ respectively of alginate particles $(\mathbf{a}, \mathbf{b})$ and chitosan particles $(\mathbf{c}, \mathbf{d})$. Fluorescent and phasecontrast images $(\times 60)$ of alginate particles inside a HN9.10e cell $(\mathbf{e}, \mathbf{f})$
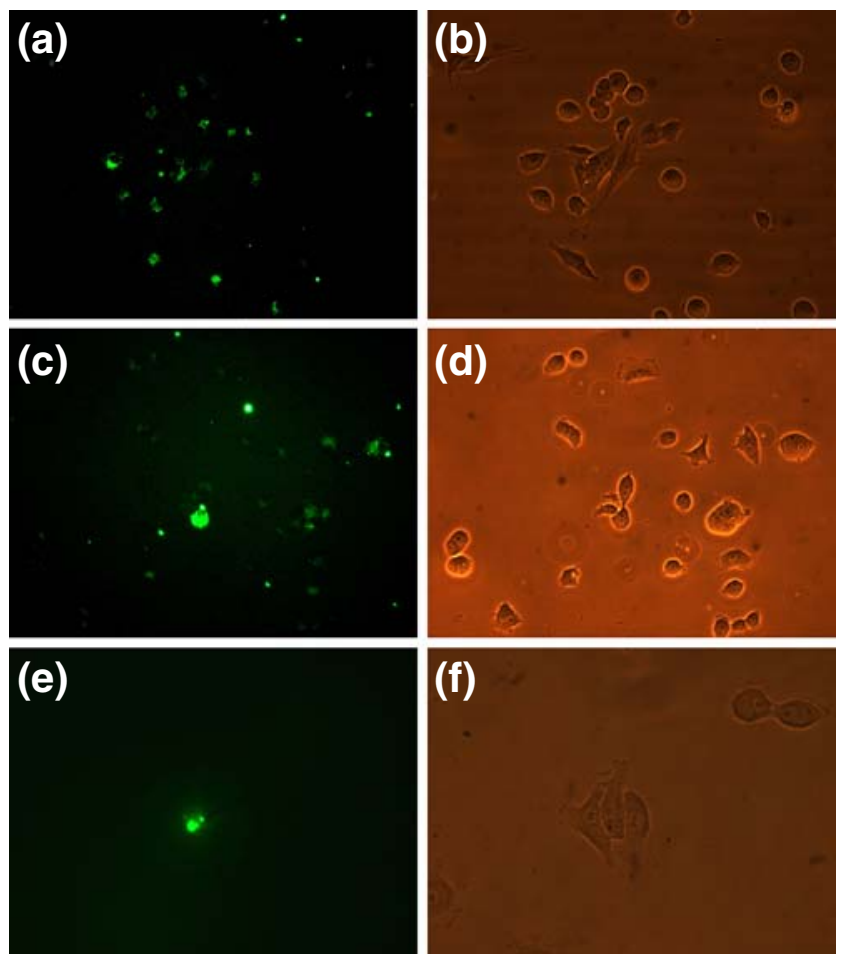

Fig. 6 Fluorescein loaded particles up-taken by CrFK cells. Fluorescent and phase-contrast images $(\times 20)$ respectively of alginate particles (a, b) and chitosan particles (c, d). Fluorescent and phase-contrast images $(\times 60)$ of alginate particles inside a $\mathrm{CrFK}$ cell $(\mathbf{e}, \mathbf{f})$
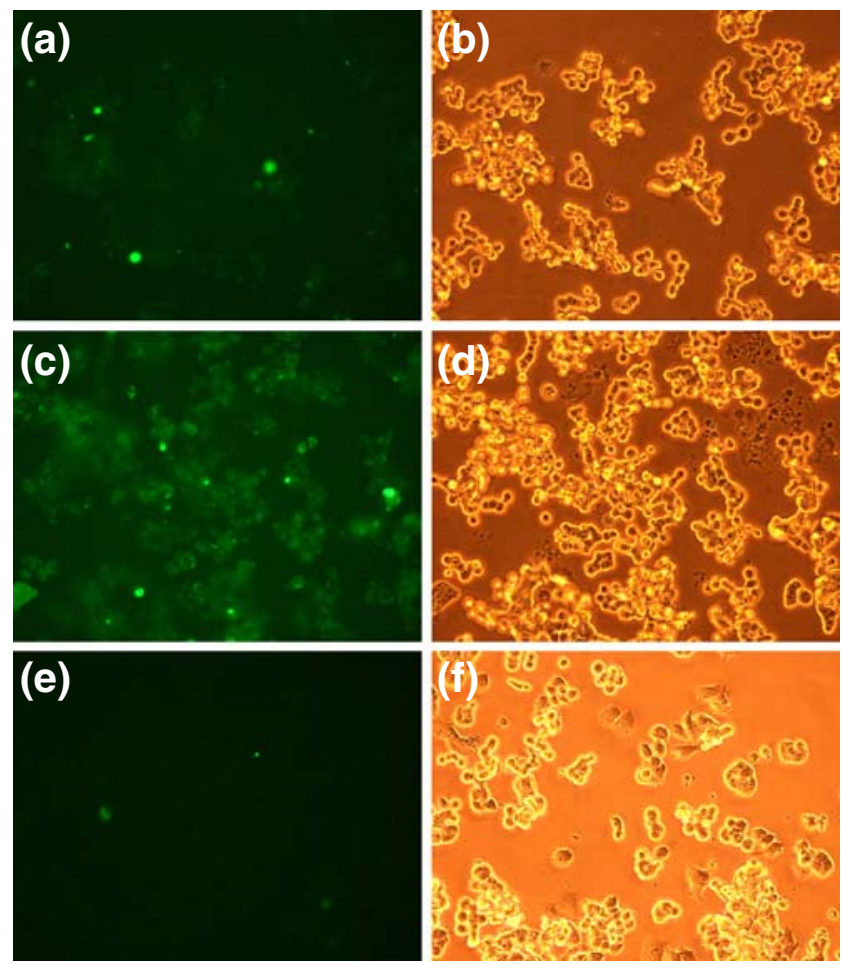

Fig. 7 Fluorescent images of lysosomal compartments of HN9.10e cells incubated with alginate particles (a), chitosan particles (c) and without particles (e). (b), (d) and (f) are the respective phase-contrast images. Magnification $\times 20$ 